\title{
Efficacy and safety of interleukin-17A inhibitors in patients with ankylosing spondylitis: a systematic review and meta-analysis of randomized controlled trials
}

\author{
Peng Wang ${ }^{1} \cdot$ Shuo Zhang ${ }^{1} \cdot$ Binwu Hu ${ }^{1} \cdot$ Weijian Liu ${ }^{1} \cdot$ Xiao Lv $^{1} \cdot$ Songfeng Chen ${ }^{2} \cdot$ Zengwu Shao $^{1}$
}

Received: 21 October 2020 / Revised: 1 December 2020 / Accepted: 10 December 2020 / Published online: 12 January 2021

(C) The Author(s) 2021

\begin{abstract}
To assess the efficacy and safety of interleukin (IL)-17A inhibitors in patients with ankylosing spondylitis (AS). PubMed, EMBASE, and Web of Science were searched up to 5 February 2020 for randomized controlled trials (RCTs) that assessed the efficacy and safety of IL-17A inhibitors in patients with AS. We used a meta-analytic approach to perform a random effects analysis or fixed effects analysis according to heterogeneity. Subgroup analyses between studies included medication, time to primary endpoint, and data source. Odds ratios (ORs) or mean differences (MDs) were used to assess the efficacy and safety of IL-17A inhibitors in AS. A total of ten RCTs with 2613 patients were eligible for inclusion in the analysis (six for secukinumab, two for ixekizumab, one for netakimab, and one for bimekizumab). Compared to placebo, IL-17A inhibitors improved ASAS20 response rate $(\mathrm{OR}=2.58 ; p<0.01)$ and ASAS40 response rate $(\mathrm{OR}=2.80 ; p<0.01)$, and significantly increased the risk of AEs $(\mathrm{OR}=1.23 ; p=0.03)$ and nasopharyngitis $(\mathrm{OR}=1.72 ; p<0.01)$, but not SAEs $(\mathrm{OR}=0.87 ; p=0.60)$. IL-17A inhibitors demonstrated better efficacy in patients with AS in several evaluation indicators. However, the safety of IL-17A inhibitors remains to be further studied in studies with larger sample size and longer follow-up times.
\end{abstract}

Keywords Ankylosing spondylitis $\cdot$ IL-17A inhibitors $\cdot$ Meta-analysis $\cdot$ Randomized controlled trial

\section{Introduction}

Ankylosing spondylitis (AS), also termed radiographic spondyloarthritis, is a primary subtype of axial spondyloarthritis. AS is a chronic inflammatory rheumatic disease, which is featured with axial inflammation, and imaging-visible structural damages in the spine and sacroiliac joints [1-3]. With an incidence of $0.02-0.35 \%$ [4], AS not only decreases the work productivity, and life quality [5], but also results in heavy burdens of public health care all over the world [6]. The molecular and pathogenesis mechanisms that underlie AS still have many dark sides. Although the exact etiology and pathogenesis mechanisms are not clear, many studies have instructed that the occurrence of AS is closely related to the positive expression of human leukocyte antigen (HLA)-B27 [7, 8]. Immune system also promotes the

Peng Wang and Shuo Zhang have contributed equally to this work.

\author{
Zengwu Shao \\ szwpro@163.com \\ Peng Wang \\ wpunion2019@163.com \\ Shuo Zhang \\ zhangshuo_hust@163.com \\ Binwu $\mathrm{Hu}$ \\ hubinwu@hust.edu.cn \\ Weijian Liu \\ m201775647@hust.edu.cn
}

\author{
Xiao Lv \\ lvxiaotjmu@163.com \\ Songfeng Chen \\ chensongfeng123@126.com \\ 1 Department of Orthopaedics, Union Hospital, Tongji Medical \\ College, Huazhong University of Science and Technology, \\ Wuhan 430022, Hubei Province, China \\ 2 Department of Orthopaedics, The First Affiliated Hospital of \\ Zhengzhou University, Zhengzhou 450052, China
}


development and progression of AS, which can be characterized by overexpression of inflammatory cytokines and abnormal activation of immune cells in AS patients.

During the past decades, researchers have kept exploring the therapies for AS. Physical therapy is proved to be efficacious for AS patients. However, its application is limited due to high expense and low accessibility [9]. For AS patients suffering from pain and stiffness, non-steroidal anti-inflammatory drugs (NSAIDs) are recommended as the first-line treatment [10]. Recently, biological disease-modifying antirheumatic drugs (bDMARDs) emerged as novel therapies for AS. For example, tumor necrosis factor (TNF) inhibitors are recommended to patients with AS who are in persistent disease activity period [10]. Nevertheless, NSAIDs and TNF inhibitors are not always effective and well-tolerated for all types of AS patients $[10,11]$. Therefore, novel therapeutic alternatives for AS are highly required.

Mounting studies have demonstrated that interleukin (IL)23/IL-17 axis was highly associated with immune dysfunction and activated autoimmune inflammation. Further studies demonstrated that IL-23/IL-17 axis was involved in the pathogenesis of multiple rheumatoid diseases, including spondyloarthritis, psoriasis, rheumatoid arthritis, and inflammatory bowel diseases [12-14]. IL-17, also named as cytotoxic T lymphocyte antigen 8 (CTLA8), was first cloned from activated T cells in 1993 [15]. IL-17 family includes six members from IL-17A to IL-17F, of which IL-17A and IL-17F are crucial proinflammatory cytokines [16]. Soon after the discovery of IL-17, the IL-17 receptor (IL-17R) family was identified consisting of five members ranging from IL-17RA to IL17RE [17]. The IL-17 members may combine with the IL17Rs [18], and then activate various inflammatory pathways, including the nuclear factor $\mathrm{KB}(\mathrm{NF}-\mathrm{kB})$ pathway, the mitogen-activated protein kinases (MAPKs) pathway, and the CCAAT/enhancer-binding proteins (C/EBPs) pathway [19]. The activation of these signal transduction pathways leads to the overexpression of various proinflammatory cytokines, such as IL-6, IL-8, TNF- $\alpha$, and IL-1 $\beta$ [18]. Notably, in the individuals with AS, serum level of IL-17 [20] and IL-23 [21] as well as the number of T helper (Th) 17 cells [22-25] in peripheral blood and facet joints [26] were increased compared with healthy control subjects.

Based on a growing body of researches, IL-17A was recognized as a novel therapeutic target for AS. Biological IL$17 \mathrm{~A}$ inhibitors, which are crucial members of bDMARDs, could directly combine with IL-17A and inhibit its function [27]. IL-17A inhibitors are well established and known as efficient and safe for the treatment of psoriasis [28], rheumatoid arthritis [29, 30], and inflammatory bowel diseases [31]. Recently, increasing randomized controlled trials (RCTs) [32-41] have investigated the efficacy and safety of IL-17A inhibitors in AS, but the clinical value of IL-17A inhibitors in AS is still an area of controversy due to different drug types and dosages. Previous meta-analysis on biological agents for AS treatment only included one or two studies about IL-17A inhibitors $[42,43]$, after that there were few newly established studies. As such, an updated quantification of the efficacy and safety of IL-17A inhibitors was warranted.

Herein, considering that a number of studies have demonstrated the impact of IL-17A inhibitors in AS, the present systematic review and meta-analysis were conducted to comprehensively understand the efficacy and safety profile of IL$17 \mathrm{~A}$ inhibitors in AS.

\section{Materials and methods}

This meta-analysis was performed in accordance with the Cochrane Handbook for Systematic Review of Interventions [44].

\section{Literature retrieval}

A comprehensive literature retrieval was carried out in PubMed, EMBASE, and Web of Science up to February 5, 2020 , by two reviewers independently. The search was performed using the terms "ixekizumab OR taltz OR LY2439821 OR secukinumab OR cosentyx OR AIN 457 OR bimekizumab OR UCB4940 OR netakimab OR Anti IL-17 OR Interleukin 17 OR IL-17 inhibitor OR Interleukin 17 inhibitor" AND "ankylosing spondylitis OR spondyloarthritis." In addition, reference lists of the relevant articles and reviews were examined carefully to identify additional eligible articles.

\section{Selection criteria}

Articles were included in this analysis if they met all the following criteria: (1) the study was a RCT; (2) patients were diagnosed as AS according to the modified New York criteria; (3) treatment groups received IL-17A inhibitors and control groups received placebo in the RCTs; (4) the efficacy or safety outcomes were reported in the RCTs; (5) the language of the articles was English. Additionally, we excluded animal studies, observational studies, reviews, commentaries, letters, and RCTs that examined other interventions. For the publications with repetitive trial numbers according to the ClinicalTrials. gov identifier, only the most recent one was included. Two authors independently screened all studies by title or abstract and then by a full text evaluation; any discrepancy was solved by discussion.

\section{Data extraction and quality assessment}

Data extraction was carried out independently by two authors using a predefined form. We extracted the following 
information from each included study as follows: first author, publication year, NCT number, region, time to primary endpoint, study duration, medication and dosage, number of cases, mean age, ratio of males, disease duration, HLA-B27positive rate, baseline data of the Bath AS disease activity index (BASDAI).

Quality assessment was performed using the Cochrane Collaboration's tool. We assessed risk of bias according to the following bias categories: random sequence generation, allocation concealment, blinding, incomplete outcome data, selective reporting, and other bias. Each segment was assessed as high risk, low risk, or unclear risk of bias.

\section{Efficacy and safety outcomes}

Primary efficacy outcomes were as follows: $20 \%$ improvement according to the Assessment of SpondyloArthritis international Society (ASAS) criteria (ASAS20 response), and $40 \%$ improvement according to ASAS criteria (ASAS40 response). Other efficacy outcomes were $20 \%$ or more improvement in five of the six ASAS response domains (ASAS5/6 response), the change from baseline in total BASDAI, and a score of $\leq 2$ units in each of the four core ASAS domains (ASAS partial remission). Safety outcomes included adverse events (AEs), serious adverse events (SAEs), nasopharyngitis, discontinuation due to any AEs (DDAAEs), infections, and serious infections.

\section{Statistical analysis}

Review Manager 5.3 was used to perform the data analysis. Odds ratios (ORs) with corresponding 95\% confidence intervals (CIs) were considered as the effect size for dichotomous variables, and mean differences (MDs) with 95\% CIs were for continuous variables. We performed Cochran I-squared test to assess the heterogeneity among studies. It was supposed that no significant heterogeneity existed among studies if $I^{2}<$ $50 \%$, and thus a fixed-effects model was applied. Otherwise, a random-effects model was considered to be more appropriate if $I^{2}>50 \%$. To explore the source of heterogeneity among studies and to test the robustness of the results, we further conducted subgroup analyses by the following factors: medication (secukinumab, ixekizumab, netakimab, or bimekizumab), time to primary endpoint ( 6 weeks, 12 weeks or 16 weeks), and data source (full-text article or conference abstract). If included studies held several treatment arms in terms of dosage, we combined relevant treatment groups into one treatment group, as the Cochrane Handbook for Systematic Review of Interventions recommended [44]. Sensitivity analysis was conducted by omitting any of the studies at a time to further evaluate the stability and credibility of the analytical results. Statistical significance was defined as $P$ value $<0.05$.

\section{Results}

\section{Study selection and characteristics of included studies}

The searching process was summarized in Fig. 1. According to the study searching strategy stated above, 370 records were identified through database searching and 10 records were obtained from the references of the identified articles. After removing 118 duplicated records, we screened the remaining 262 records and excluded 194 records according to the title and the abstract. Then, full texts of the remaining 68 articles were viewed carefully, and 58 of them were excluded. Finally, ten RCTs with 2613 patients were included in our metaanalysis in total, of which seven were published in articles and three were reported in conference abstracts.

Among ten eligible studies in this meta-analysis, there were six studies for secukinumab, two studies for ixekizumab, one study for netakimab, and one study for bimekizumab. Characteristics of included studies were summarized in Table 1. In summary, (1) the year of publication ranged from 2013 to 2019; (2) the sample size ranged from 30 to 458; (3) the time to primary endpoint was 6 weeks for Baeten (2013) [32], 12 weeks for van der Heijde (2018) (2) [41], and 16 weeks for other eight studies; (4) mean age of patients ranged from 40.1 to 47.4 years; (5) the ratio of males ranged from 52.6 to $84.5 \%$; (6) mean disease duration ranged from 5.2 to 13 years; (7) eight studies [33-35, 37-41] had different treatment arms based on dosage; (8) nine studies [32-34, 36-41] declared that they were sponsored. After the time of primary endpoint, all patients in both the treatment groups and the placebo groups entered an extended treatment period and received IL-17A inhibitors treatment. It should be noted that one patient in the treatment group of Baeten (2013) [32] was excluded from the efficacy analysis but included in the safety analysis due to a dosing error. The quality and the risks of bias of included studies were presented in Fig. 2. Notably, there were three RCTs being reported in conference abstracts respectively, and comprehensive information and data were not available.

\section{Efficacy of IL-17A inhibitors}

\section{ASAS20 response}

ASAS20 response was defined as an outcome that patients achieved 20\% improvement according to ASAS criteria. As a primary efficacy outcome indicator for AS, ASAS20 response was reported in nine studies consisting of 2309 patients. No significant heterogeneity among the RCTs was detected $\left(I^{2}=18 \%\right)$, and thus a fixed-effects model was performed. Compared with placebo, IL-17A inhibitors significantly improved the rate of ASAS20 response $(\mathrm{OR}=2.58$; 95\% CI, 2.16 to $3.09 ; p<0.01$ ) (Fig. 3A). Subgroup analyses 
Fig. 1 Flowchart of study selection process

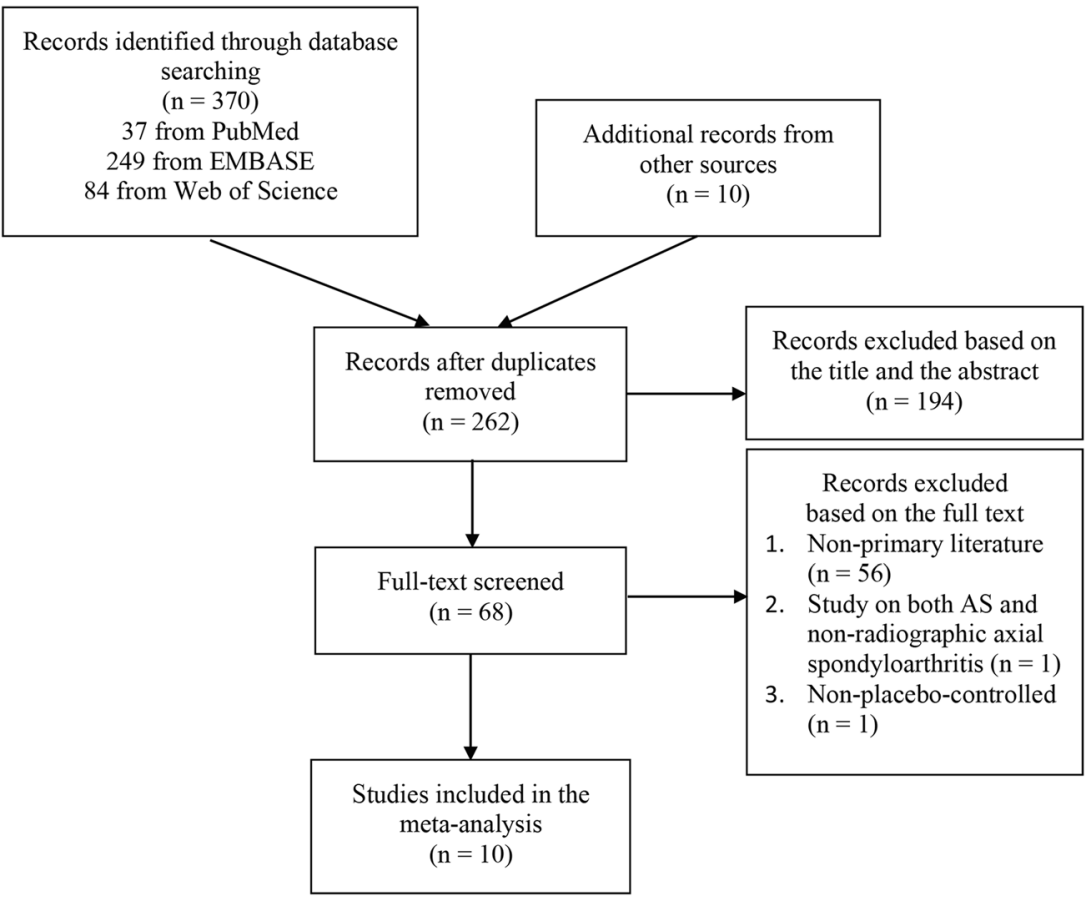

were performed according to three factors: medication (secukinumab, ixekizumab, or netakimab), time to primary endpoint (6 weeks or 16 weeks), and data source (full text or conference abstract) (Table 2). The results indicated that the efficacy of IL-17A inhibitors on ASAS20 response kept significant in the subgroup analyses. Furthermore, we performed sensitivity analysis and the result showed that the statistical significance was not altered after omitting any of the studies, further confirming the stability and credibility of the eventual results.

\section{ASAS40 response}

ASAS40 response was also a crucial outcome indicator which represented patients achieved $40 \%$ improvement according to ASAS criteria. Seven studies with 1762 patients were included in the analysis of ASAS40 response. A fixed-effects model was more appropriate due to non-significant heterogeneity $\left(I^{2}=41 \%\right)$. IL-17A inhibitors made a significant improvement on ASAS40 response rate in $\mathrm{AS}(\mathrm{OR}=2.80 ; 95 \% \mathrm{CI}, 2.19$ to 3.58; $p<0.01$ ) (Fig. 3B). We further conducted subgroup analyses and we found that the efficacy of IL-17A inhibitors on ASAS40 response remained significant and the outcomes were presented in Table 2. Additionally, sensitivity analysis was performed and the result remained significant after omitting single study one by one.

\section{Other efficacy outcomes}

There were five studies reporting data for ASAS5/6 response, four studies for the change from baseline in total BASDAI, and three studies for ASAS partial remission. Random effect model was suitable for the analyses of ASAS5/6 response $\left(I^{2}=75 \%\right)$ and the change from baseline in total BASDAI $\left(I^{2}=100 \%\right)$ owing to obvious heterogeneity. However, in the analysis of ASAS partial remission $\left(I^{2}=0 \%\right)$, no heterogeneity between the RCTs was detected and thus the fixedeffects model was performed. The results indicated that IL17A inhibitors could significantly improve ASAS5/6 response rate $(\mathrm{OR}=4.01 ; 95 \% \mathrm{CI}, 2.00$ to $8.02 ; p<0.01)$ (Fig. 3C) and ASAS partial remission rate $(\mathrm{OR}=5.93 ; 95 \% \mathrm{CI}, 2.83$ to 12.45; $p<0.01$ ) (Fig. 3D), and reduce BASDAI score $(\mathrm{MD}=-1.13 ; 95 \% \mathrm{CI},-1.72$ to $-0.55 ; p<0.01)$ (Fig. $3 \mathrm{E})$, indicating the favorable curative effects of IL-17A inhibitors in AS. Sensitivity analyses showed that removing any of the studies did not influence the results significantly.

\section{Safety of IL-17A inhibitors}

\section{AEs}

Eight studies with 2066 patients were included in the analysis of AEs. No heterogeneity between the RCTs was detected $\left(I^{2}=0 \%\right)$ and a fixed-effects model was performed. Comparing to placebo, IL-17A inhibitors increased risk of AEs $(\mathrm{OR}=1.23 ; 95 \% \mathrm{CI}, 1.02$ to $1.49 ; p=0.03)$ (Fig. $4 \mathrm{~A})$. We performed subgroup analyses and found that ixekizumab $(\mathrm{OR}=1.44 ; 95 \% \mathrm{CI}, 1.01$ to $2.05 ; p=0.04)$ rather than secukinumab $(\mathrm{OR}=1.20 ; 95 \% \mathrm{CI}, 0.94$ to $1.53 ; p=0.15)$ increased the risk of AEs (Table 2). When we removed Deodhar (2016) [33] or Deodhar (2019) [34], the results were altered to 


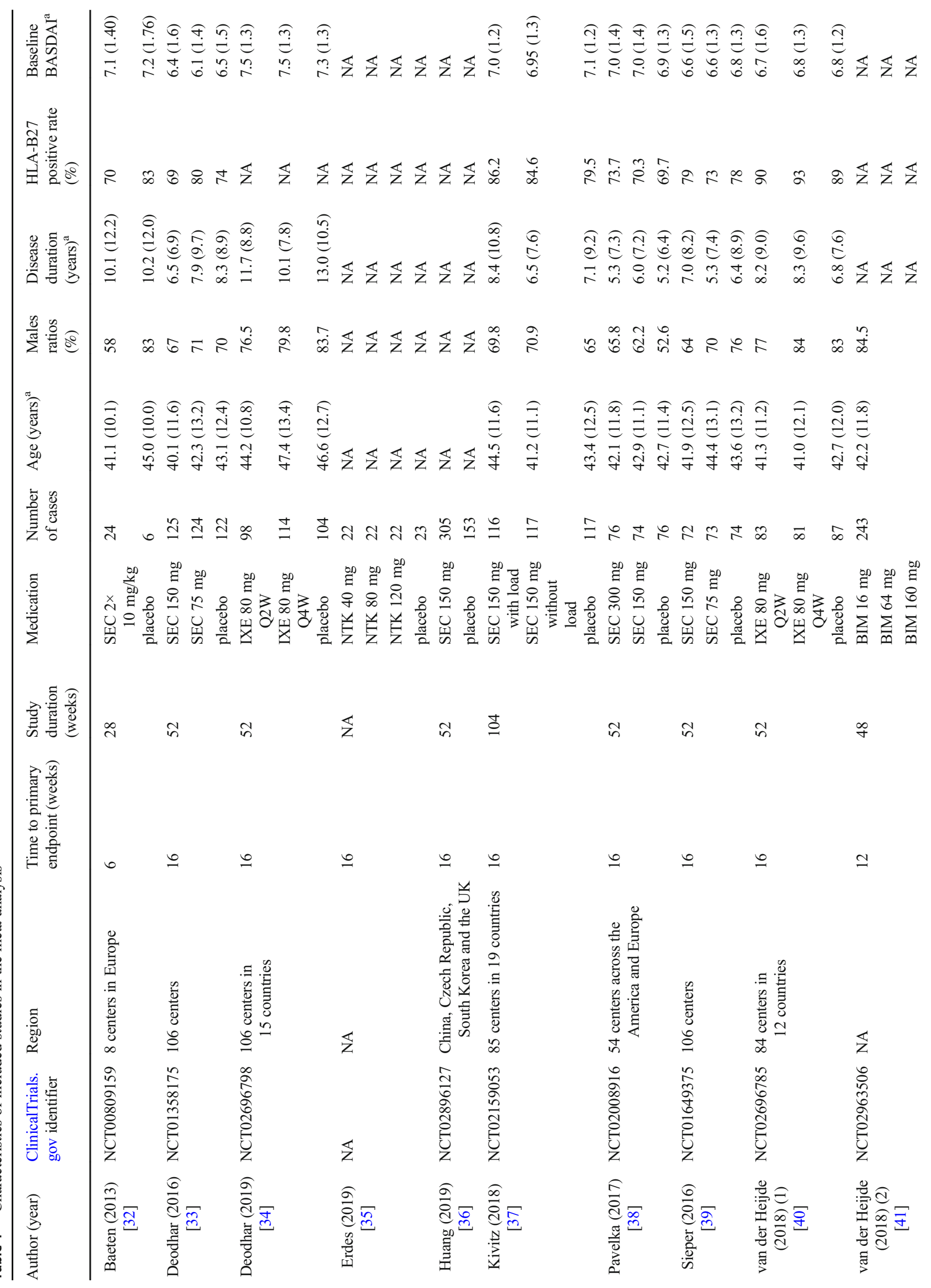


be insignificant ( $p=0.21$ or 0.18 , respectively), indicating that increased risk of AEs might be derived from these two studies.

\section{SAEs}

Eight studies with 2221 patients were included in the analysis of SAEs. A fixed-effects model was performed in the analysis of SAEs $\left(I^{2}=0 \%\right)$. Meta-analysis of SAEs demonstrated that IL-17A inhibitors did not increase the risk of SAEs (OR = $0.87 ; 95 \% \mathrm{CI}, 0.51$ to $1.48 ; p=0.60$ ) (Fig. 4B). We further conducted subgroup analyses. The result did not indicate statistically significant differences between secukinumab and placebo $(\mathrm{OR}=0.87 ; 95 \% \mathrm{CI}, 0.47$ to $1.61 ; p=0.66)$, as well as ixekizumab and placebo ( $\mathrm{OR}=0.86 ; 95 \% \mathrm{CI}, 0.30$ to 2.49 ; $p=0.41$ ) (Table 2). Removing any of the studies did not influence the result significantly.

\section{Nasopharyngitis}

Nasopharyngitis was the most commonly reported adverse event among these studies. Seven studies with 1763 patients were included in the analysis of nasopharyngitis. No heterogeneity among the RCTs was detected $\left(I^{2}=0 \%\right)$ and a fixedeffects model was performed. Comparing to placebo, IL-17A inhibitors increased the risk of nasopharyngitis $(\mathrm{OR}=1.72$; 95\% CI, 1.15 to $2.57 ; p<0.01$ ) (Fig. 4 C). The result of subgroup analyses indicated that secukinumab $(\mathrm{OR}=1.84 ; 95 \%$ $\mathrm{CI}, 1.16$ to $2.94 ; p=0.01)$ rather than ixekizumab $(\mathrm{OR}=1.39$; $95 \% \mathrm{CI}, 0.63$ to $3.06 ; p=0.41)$ increased the risk of nasopharyngitis (Table 2). Removing any of the studies did not influence the result significantly.

\section{DDAAEs and deaths}

There were five studies reporting data for DDAAEs. No heterogeneity was detected in the analysis of DDAAEs $\left(I^{2}=\right.$ $37 \%$ ) and a fixed-effects model was performed. IL-17A inhibitors showed no impact on DDAAEs (OR $=1.19 ; 95 \% \mathrm{CI}$, 0.61 to $2.32 ; p=0.62$ ) (Fig. 4D). As for deaths, one death occurred in the placebo group in Deodhar (2016) [33] due to depression and suicide, one death occurred in the treatment group of secukinumab $75 \mathrm{mg}$ in Sieper (2016) [39], and one death occurred in the treatment group of ixekizumab $80 \mathrm{mg}$ every 2 weeks (Q2W) in Deodhar (2019) as a result of depression and suicide [34]. The impact of IL-17A inhibitors on the risk of death was not analyzed owing to limited data.

\section{Infections and serious infections}

Four studies were included for the analysis of infections. Significant heterogeneity was detected in the analysis of infections $\left(I^{2}=58 \%\right)$ and the random-effects model was performed. IL-17A inhibitors increased the risk of infections 


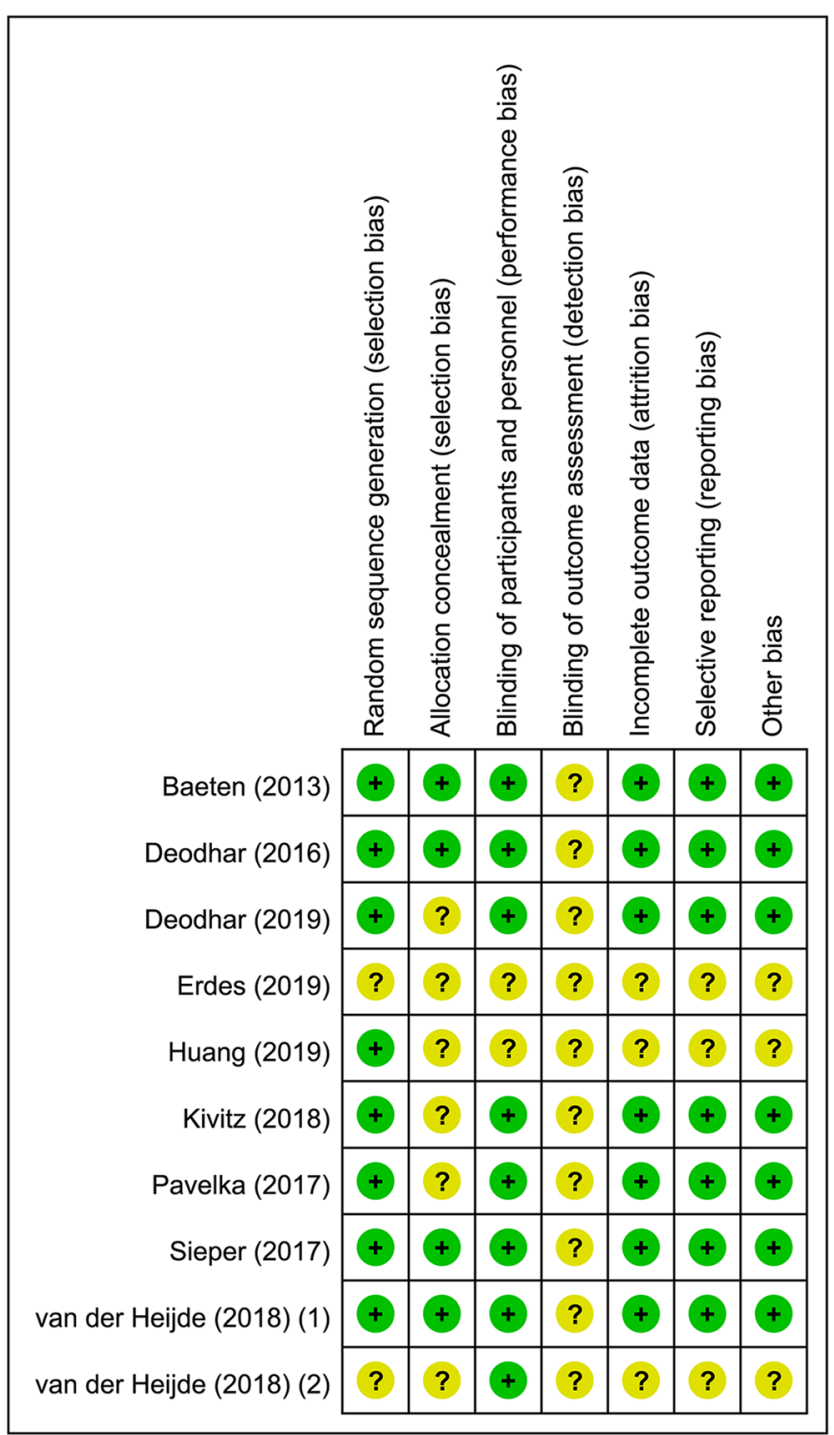

Fig. 2 The quality of included studies evaluated by the Cochrane Collaboration's tool

$(\mathrm{OR}=2.08 ; 95 \% \mathrm{CI}, 1.25$ to $3.47 ; p<0.01)$ (Fig. 4E). In addition, there were totally 5 serious infections among the included patients: 1 patient in the treatment group of secukinumab $150 \mathrm{mg}$ with a loading regimen (secukinumab $150 \mathrm{mg}$ with load) in Kivitz (2018) [37], 2 patients in treatment group of ixekizumab $80 \mathrm{mg}$ every 4 weeks (Q4W) in Deodhar (2019) [34], and 2 patient in the treatment groups in van der Heijde (2018) (1) [40]. Meta-analysis of serious infections did not indicate statistically significant differences between treatment and control groups $(\mathrm{OR}=2.23 ; 95 \% \mathrm{CI}$, 0.38 to $13.21 ; p=0.38$ ) (Fig. $4 \mathrm{~F}$ ).

\section{Discussion}

AS, a part of a larger class of spondyloarthropathies, is a relatively common, chronic, and serious autoimmune disease mainly affecting the axial skeleton and spinal joints, eventually reducing the quality of life, also extorting heavy economic burdens and pressure on individuals and the society. As the disease progresses, ankylosis is a major characteristic of AS in advanced cases, leading to the fusion of vertebrae, decreased mobility, and increased long-term disability. Notably, although there are many available treatments to effectively relieve the symptoms of AS, there is no cure method currently. The treatment options for patients with AS were really limited. In recent years, the potential application of bDMARDs has gradually attracted extensive attention of researchers, and the clinical management of AS has been significantly changed as a result of the introduction of bDMARDs.

IL-17, mainly produced by Th17 cells, plays a crucial role in protecting hosts from bacterial and fungal infections under physiological condition. In addition, IL-17 could improve the expression of various proinflammatory cytokines and further lead to inflammatory activation. Recently, IL-17A inhibitors were proved to be novel bDMARDs for several autoimmune diseases, including psoriasis [28], rheumatoid arthritis [29, 30], and inflammatory bowel disease [31]. Overexpressed IL-17 was also highly involved in the autoimmune dysfunction and the disease progression in AS patients. However, the clinical value of IL-17A inhibitors is still controversial. To our best knowledge, the current meta-analysis is the first to comprehensively evaluate the efficacy and safety of IL-17A inhibitors in patients with AS.

Through pooling the data of 10 independent RCTs and comprehensively analyzing the ASAS20 response, ASAS40 response, ASAS5/6 response, and ASAS partial remission, we found that IL-17A inhibitors significantly alleviated the clinical signs and symptoms of AS. In addition, disease activity was controlled by IL-17A inhibitors as measured by decreased BASDAI. Significant heterogeneity was detected in the analysis of ASAS5/6 response and BASDAI, which may reduce the credibility of the data to some extent. Furthermore, after the time of primary endpoint, all patients in both the treatment groups and the placebo groups entered an extended treatment period and received IL-17A inhibitors. There are 7 extension studies reporting that secukinumab possesses sustained efficacy in AS through 1 to 5 years [45-51]. Similarly, the extension studies of ixekizumab demonstrated that the efficacy through 52 weeks was consistent with 16 weeks [52]. Therefore, IL17A inhibitors demonstrated favorable curative effects in patients with AS and were expected to be promising drugs for AS.

AEs, nasopharyngitis, and infections were found to be more frequently in treatment groups compared with placebo. However, there was no evidence that IL-17A inhibitors increased the risk of SAEs, serious infections, and DDAAEs. As for the death risk, OR was not obtained owing to limited data. To be specific, there were totally three deaths in the included trials, two of which happened in the treatment 
Table 2 The results of subgroup analyses by factors of medication, time to primary endpoint, and data source

\begin{tabular}{|c|c|c|c|c|c|}
\hline Outcome & Subgroup & No. of studies & No. of patients & OR $(95 \% \mathrm{CI})$ & $P$ value \\
\hline \multicolumn{6}{|l|}{ Medication } \\
\hline \multirow[t]{3}{*}{ ASAS20 } & SEC & 6 & 1653 & $2.54(2.05,3.14)$ & $<0.01$ \\
\hline & IXE & 2 & 567 & $2.47(1.72,3.57)$ & $<0.01$ \\
\hline & NET & 1 & 89 & $5.85(2.08,16.47)$ & $<0.01$ \\
\hline \multirow[t]{2}{*}{ ASAS40 } & SEC & 5 & 1195 & $2.54(1.90,3.41)$ & $<0.01$ \\
\hline & IXE & 2 & 567 & $3.49(2.22,5.48)$ & $<0.01$ \\
\hline \multirow[t]{3}{*}{ AEs } & SEC & 5 & 1196 & $1.20(0.94,1.53)$ & 0.15 \\
\hline & IXE & 2 & 567 & $1.44(1.01,2.05)$ & 0.04 \\
\hline & BIM & 1 & 303 & $0.93(0.52,1.66)$ & 0.81 \\
\hline \multirow[t]{2}{*}{ Nasopharyngitis } & SEC & 5 & 1196 & $1.84(1.16,2.94)$ & 0.01 \\
\hline & IXE & 2 & 567 & $1.39(0.63,3.06)$ & 0.41 \\
\hline \multirow[t]{2}{*}{ SAEs } & SEC & 6 & 1654 & $0.87(0.47,1.61)$ & 0.66 \\
\hline & IXE & 2 & 567 & $0.86(0.30,2.49)$ & 0.78 \\
\hline \multicolumn{6}{|l|}{ Time to endpoint } \\
\hline \multirow[t]{2}{*}{ ASAS20 } & 6 weeks & 1 & 29 & $7.78(0.78,77.93)$ & 0.08 \\
\hline & 16 weeks & 8 & 2280 & $2.56(2.14,3.07)$ & $<0.01$ \\
\hline \multirow[t]{2}{*}{ ASAS40 } & 6 weeks & 1 & 29 & $2.19(0.21,22.34)$ & 0.51 \\
\hline & 16 weeks & 6 & 1733 & $2.81(2.19,3.59)$ & $<0.01$ \\
\hline \multirow[t]{3}{*}{ AEs } & 6 weeks & 1 & 30 & $1.21(0.04,33.21)$ & 0.91 \\
\hline & 12 weeks & 1 & 303 & $0.93(0.52,1.66)$ & 0.81 \\
\hline & 16 weeks & 6 & 1733 & $1.27(1.04,1.56)$ & 0.02 \\
\hline \multirow[t]{2}{*}{ Nasopharyngitis } & 6 weeks & 1 & 30 & $5.57(0.28,112.01)$ & 0.26 \\
\hline & 16 weeks & 6 & 1733 & $1.66(1.11,2.50)$ & 0.01 \\
\hline \multirow[t]{2}{*}{ SAEs } & 6 weeks & 1 & 30 & $0.83(0.03,22.87)$ & 0.91 \\
\hline & 16 weeks & 7 & 2191 & $0.87(0.51,1.49)$ & 0.61 \\
\hline \multicolumn{6}{|l|}{ Data source } \\
\hline \multirow[t]{2}{*}{ ASAS20 } & Full text & 7 & 1762 & $2.55(2.07,3.13)$ & $<0.01$ \\
\hline & Conference abstract & 2 & 547 & $2.70(1.86,3.92)$ & $<0.01$ \\
\hline \multirow[t]{2}{*}{ AEs } & Full text & 7 & 1763 & $1.27(1.04,1.56)$ & 0.02 \\
\hline & Conference abstract & 1 & 303 & $0.93(0.52,1.66)$ & 0.81 \\
\hline \multirow[t]{2}{*}{ SAEs } & Full text & 7 & 1763 & $0.74(0.41,1.33)$ & 0.32 \\
\hline & Conference abstract & 1 & 458 & $1.69(0.46,6.25)$ & 0.43 \\
\hline
\end{tabular}

$S E C$, secukinumab; $I X E$, ixekizumab; NTK, netakimab; BIM, bimekizumab

groups. Furthermore, IL-17A inhibitors may increase the risk of neutropenia owing to the immunosuppressive properties of these biologics [33, 34]. Therefore, attention should be paid to this problem when applying IL-17A inhibitors in the treatment of AS. Since this finding was based on a relatively small number of studies, the results should be interpreted prudently. Likewise, the safety of IL-17A inhibitors was controversial in other autoimmune diseases. A meta-analysis of twenty-seven RCTs showed that IL-17A inhibitors increased the risk of AEs in moderate-to-severe plaque psoriasis [53]. In addition, the risk of AEs but not SAEs was increased by IL-17A inhibitors in patients with psoriasis and psoriatic arthritis [54]. However, Kunwar et al. performed a meta-analysis of seven RCTs about rheumatoid arthritis and reported that IL-17A inhibitors did not significantly increase the risk of AEs or SAEs in rheumatoid arthritis [55]. Therefore, the safety of IL-17A inhibitors remains to be further studied.

As a consequence of the introduction of bDMARDs, TNF inhibitors were considered as usual first-line bDMARDs treatment. However, due to intolerance and inefficacy of TNF inhibitors, IL-17A inhibitors as a novel bDMARDs were recommended for AS patients who do not respond to TNF inhibitors according to 2016 update of the ASAS-EULAR management recommendations for axial spondyloarthritis [10]. Moreover, a cost-effectiveness analysis in Finland indicated that secukinumab was less costly and more effective compared to adalimumab, certolizumab pegol, etanercept, golimumab, and infliximab in AS treatment [56]. Also, 
Fig. 3 The efficacy evaluation of IL-17A inhibitors in AS. Forest plots of ORs for ASAS20 response (A), ASAS40 response (B), ASAS5/6 response (C), and ASAS partial remission (D) in patients with AS. Forest plots of MD for BASDAI (E) in patients with AS a

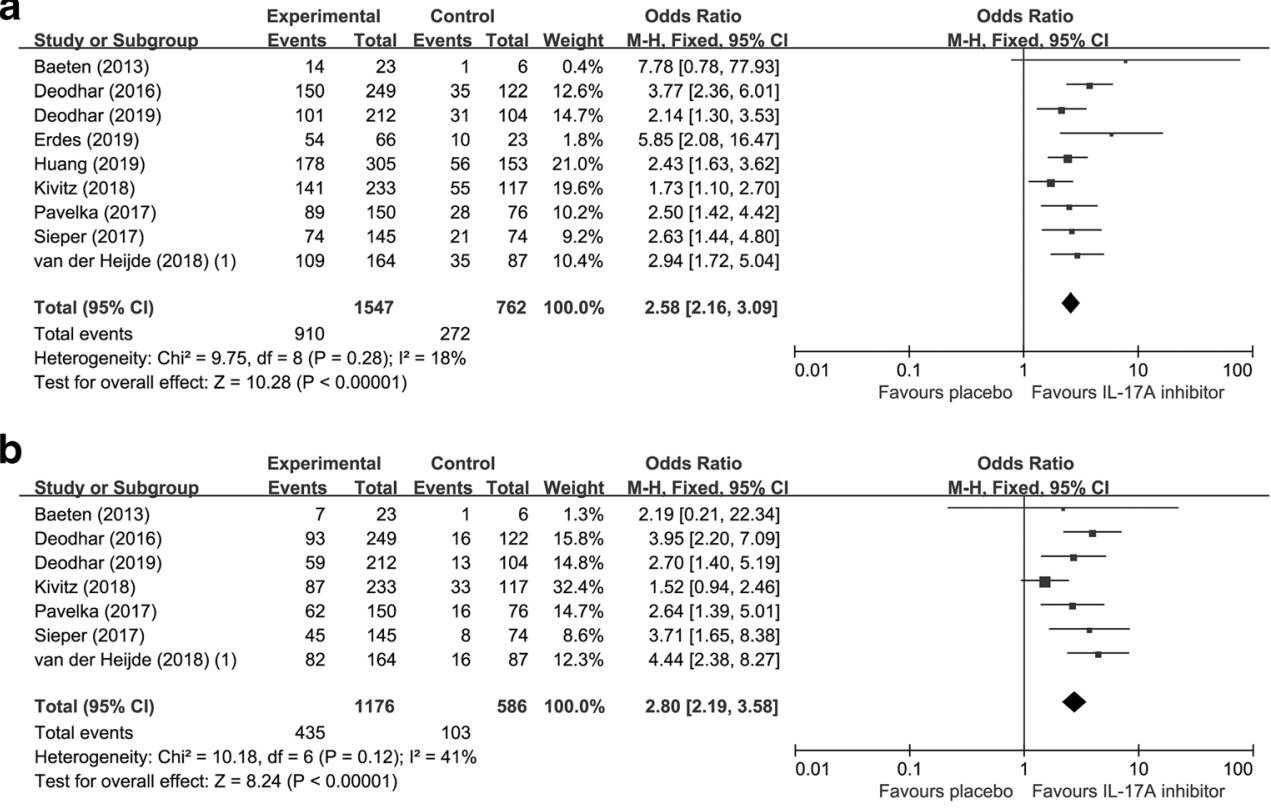

C

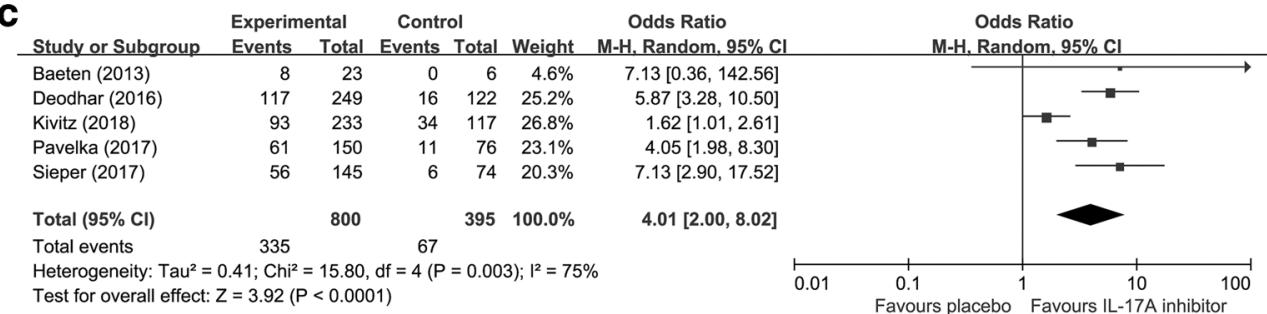

d

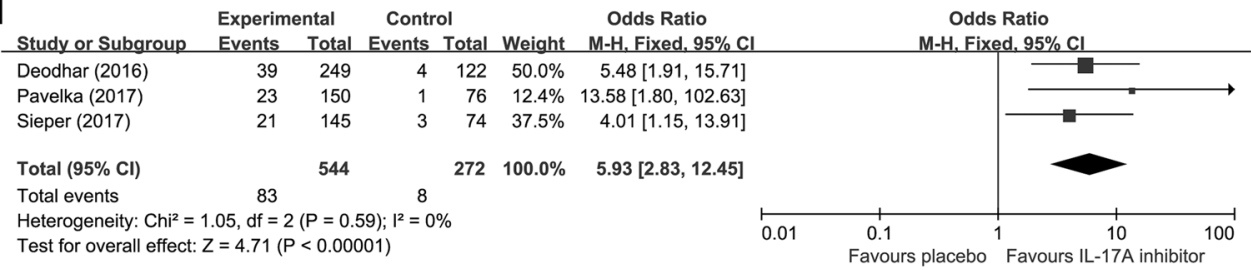

e

\begin{tabular}{|c|c|c|c|c|c|c|c|c|c|c|c|}
\hline \multirow[b]{2}{*}{ Study or Subgroup } & \multicolumn{3}{|c|}{ Experimental } & \multicolumn{3}{|c|}{ Control } & \multicolumn{2}{|c|}{ Mean Difference } & \multirow{2}{*}{\multicolumn{2}{|c|}{ Mean Difference }} & \\
\hline & Mean & SD & Total & Mean & SD & Total & Weight & IV. Random. $95 \% \mathrm{Cl}$ & & & \\
\hline Deodhar (2016) & -2.33 & 0.17 & 249 & -0.59 & 0.18 & 122 & $25.0 \%$ & $-1.74[-1.78,-1.70]$ & "I & & \\
\hline Kivitz (2018) & -2.5 & 0.23 & 233 & -1.86 & 0.2 & 117 & $25.0 \%$ & $-0.64[-0.69,-0.59]$ & & $=$ & \\
\hline Pavelka (2017) & -2.5 & 0.35 & 150 & -1.5 & 0.3 & 76 & $24.9 \%$ & $-1.00[-1.09,-0.91]$ & - & & \\
\hline Sieper (2017) & -2 & 0.28 & 145 & -0.85 & 0.25 & 74 & $25.0 \%$ & $-1.15[-1.22,-1.08]$ & $=$ & & \\
\hline Total $(95 \% \mathrm{Cl})$ & & & 777 & & & 389 & $100.0 \%$ & $-1.13[-1.72,-0.55]$ & & & \\
\hline $\begin{array}{l}\text { Heterogeneity: } \mathrm{Tau}^{2}= \\
\text { Test for overall effect: }\end{array}$ & $\begin{array}{l}0.36 ; C h \\
z=3.78\end{array}$ & & $\begin{array}{l}21.59, \\
.0002)\end{array}$ & & & & 100 & & -1 & $\begin{array}{ccc}-0.5 & 0 & 0.5 \\
& 1\end{array}$ & $\begin{array}{c}1 \\
1 \\
1\end{array}$ \\
\hline
\end{tabular}

secukinumab was proved to be the most cost-effective treatment option versus other biologics in AS by numerous researches conducted in Canada [57], Argentina [58], the UK [59], and Russia [60].

Besides the 10 included RCTs, more trials are planned or conducted to further evaluate the efficacy and safety of IL$17 \mathrm{~A}$ inhibitors in AS. In detail, there are three ongoing or planned studies for secukinumab (identifier: NCT03259074, NCT02763046, NCT03350815), two for bimekizumab (identifier: NCT03215277 and NCT03355573), and one for netakimab (identifier: NCT03447704). Because these studies are not completed, we have had no access to the relevant data so far. Therefore, we will pay close attention to the progress of these studies in the future.

Some potential limitations in our study should be acknowledged. First, we could not obtain the comprehensive information and data of three included RCTs reported in three conference abstracts respectively $[35,36,41]$. Second, the number of RCTs included in this study was still relatively small, especially for a certain type of medication, there were only two 
Fig. 4 The safety evaluation of IL-17A inhibitors in AS. Forest plots of ORs for AEs (A), SAEs (B), nasopharyngitis (C),

DDAAEs (D), infections (E), and serious infections a

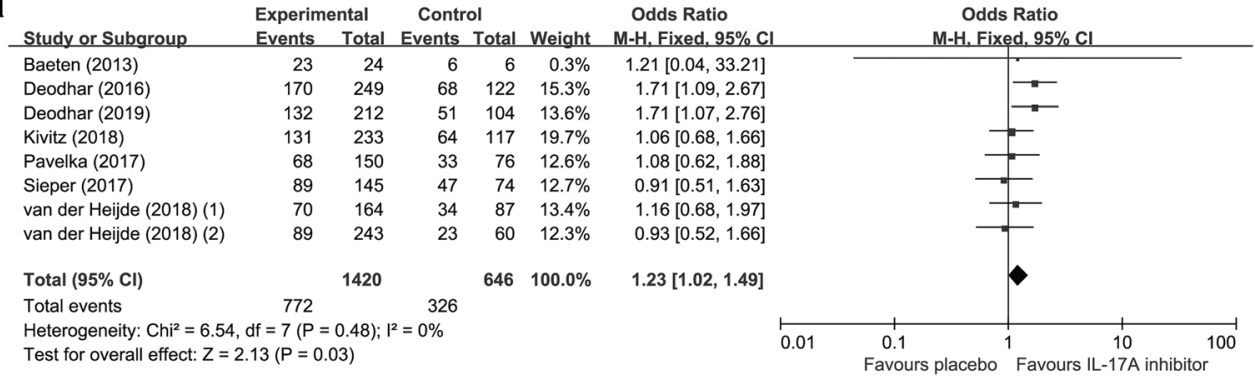

b

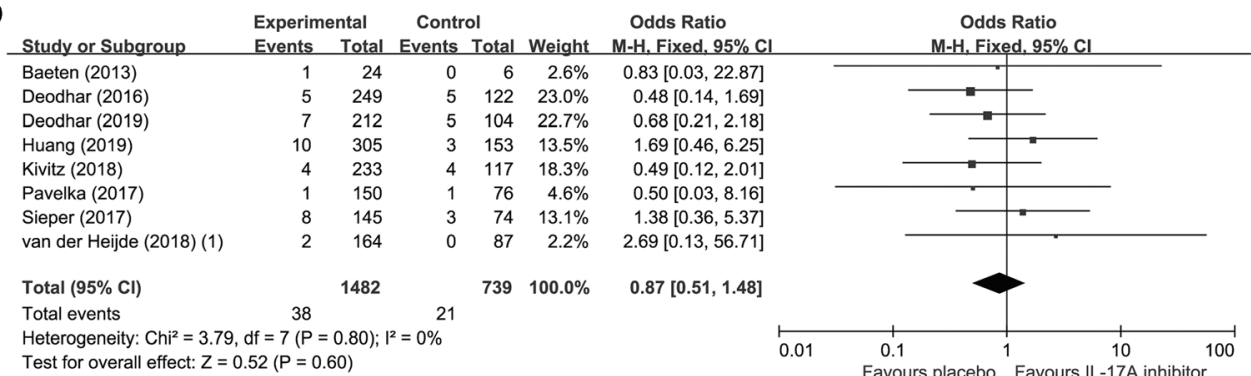

C

$\begin{array}{llll} & \text { Experimental Control } & \text { Odds Ratio } & \text { Odds Ratio }\end{array}$

Events Total Events Total Weight M-H. Fixed. 95\% C

\begin{tabular}{lrrrrrr} 
Deodhar (2016) & 7 & 24 & 0 & 6 & $1.4 \%$ & $5.57[0.28,112.01]$ \\
\hline & 30 & 249 & 9 & 122 & $26.5 \%$ & $1.72[0.79,3.75]$
\end{tabular}

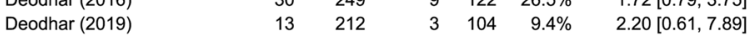

$\begin{array}{lllrrrr}\text { Deodhar (2019) } & 13 & 212 & 3 & 104 & 9.4 \% & 2.20[0.61,7.89] \\ \text { Kivitz (2018) } & 28 & 233 & 10 & 117 & 29.2 \% & 1.46[0.68,3.12]\end{array}$

$\begin{array}{lrrrrrr}\text { Kivitz (2018) } & 28 & 233 & 10 & 117 & 29.2 \% & 1.46[0.68,3.12] \\ \text { Pavelka (2017) } & 9 & 150 & 2 & 76 & 6.2 \% & 2.36[0.50,11.21]\end{array}$

$\begin{array}{lrrrrrr}\text { Pavelka (2017) } & 9 & 150 & 2 & 76 & 6.2 \% & 2.36[0.50,11.21] \\ \text { Sieper (2017) } & 14 & 145 & 3 & 74 & 9.0 \% & 2.53[0.70,9.10]\end{array}$

$\begin{array}{lllllll}\text { van der Heijde (2018) (1) } & 11 & 164 & 6 & 87 & 18.3 \% & 0.97[0.35,2.72]\end{array}$

$\begin{array}{lllll}\text { Total }(95 \% \mathrm{Cl}) & 1177 & 586 & 100.0 \% & 1.72[1.15,2.57]\end{array}$

Total events $112 \quad 33$

Heterogeneity: $\mathrm{Chi}^{2}=2.60, \mathrm{df}=6(\mathrm{P}=0.86) ; \mathrm{I}^{2}=0 \%$

Test for overall effect: $Z=2.64(P=0.008)$

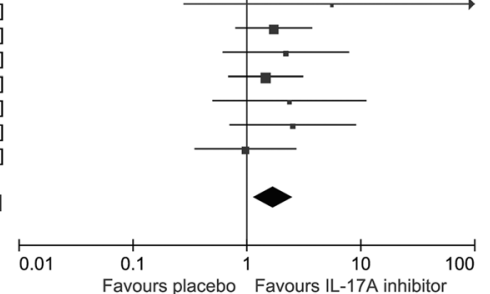

d

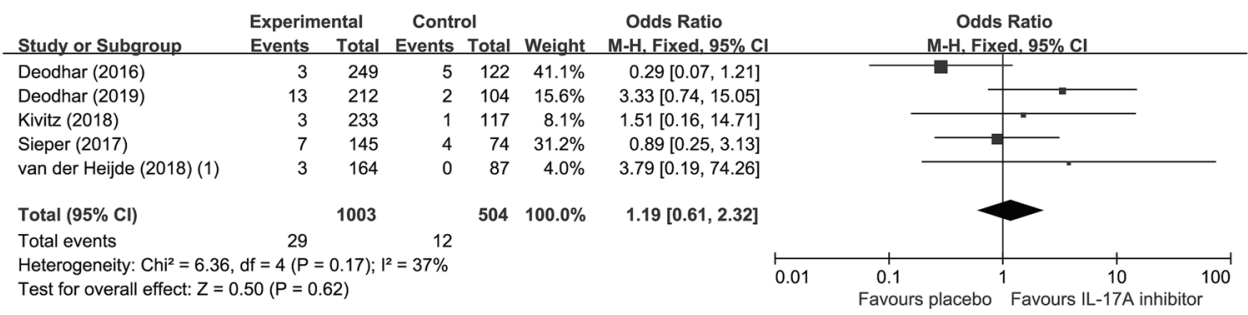

e

$\begin{array}{lll} & \text { Experimental Control } & \text { Odds Ratio } \\ \text { Study or Subgroup } & \text { Events Total Events Total Weight } & \text { M-H. Random.95\% }\end{array}$ Study or Subgroup Events Total Events Total Weight M-H. Random, 95\% Cl M-H, Random, 95\%

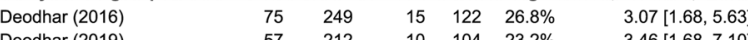
$\begin{array}{lllllll}\text { Deodhar (2019) } & 57 & 212 & 10 & 104 & 23.2 \% & 3.46[1.68,7.10]\end{array}$ $\begin{array}{lllllll}\text { Sieper (2017) } & 46 & 145 & 20 & 74 & 26.3 \% & 1.25[0.67,2.33]\end{array}$ van der Heijde (2018) (1) $\quad 33 \quad 164 \quad 13 \quad 87 \quad 23.7 \% \quad 1.43[0.71,2.89]$

$\begin{array}{lllll}\text { Total }(95 \% \mathrm{Cl}) & 770 & 387 & 100.0 \% & 2.08\end{array}[1.25,3.47]$

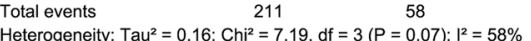
Test for overall effect: $Z=2.82(P=0.005)$ (P $=0.07) ;\left.\right|^{2}=58 \%$
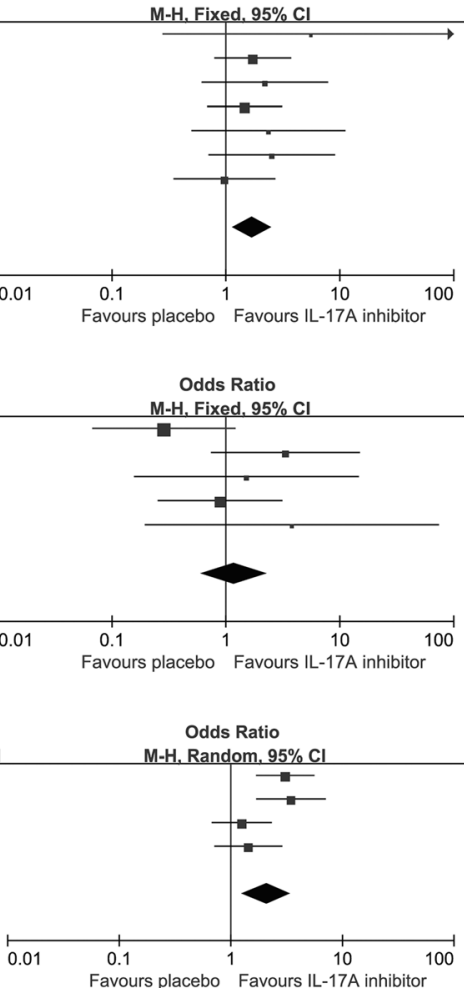

f

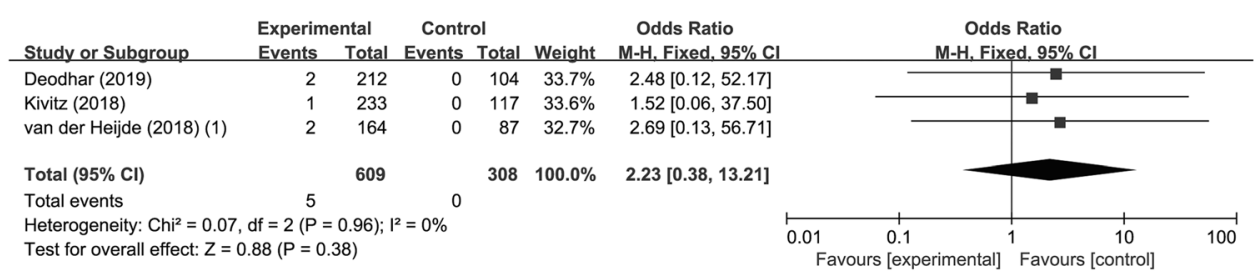


studies available for ixekizumab, one study for netakimab and one study for bimekizumab. More trials are warranted in the future to further assess the efficacy and safety of IL-17A inhibitors in AS. Third, dose-effect relationship of IL-17A inhibitors was not analyzed due to various kinds of medications and limited trials for each. In addition, different treatment arms in eight included studies were combined into one treatment group respectively.

In conclusion, the results from this meta-analysis showed that IL-17A inhibitors significantly improved clinical signs and symptoms of AS, which supported the application of IL$17 \mathrm{~A}$ inhibitors in the treatment of AS. However, studies with larger sample size and longer follow-up times are firmly warranted to evaluate the safety of IL-17A inhibitors in AS.

Authors' contributions Zengwu Shao designed the outline of the metaanalysis and edited the work. Peng Wang and Binwu Hu performed literature retrieval and screened the studies. Peng Wang and Shuo Zhang extracted data and performed statistical analysis. Peng Wang and Binwu Hu drafted the manuscript. Zengwu Shao and Shuo Zhang revised the manuscript. Weijian Liu, Xiao Lv, and Songfeng Chen created the tables and figures. All authors approved the manuscript.

Funding This work was supported by The National Key Research and Development Program of China [grant numbers 2016YFC1100100]; the Major Research Plan of National Natural Science Foundation of China [grant numbers 91649204].

Data availability Not applicable.

\section{Compliance with ethical standards}

\section{Disclosures None.}

Code availability Not applicable.

Abbreviations IL, interleukin; AS, ankylosing spondylitis; RCT, randomized controlled trial; ASAS, the Assessment of SpondyloArthritis International Society; ASAS20, 20\% improvement according to ASAS criteria; ASAS40, 40\% improvement according to ASAS criteria; BASDAI, Bath AS disease activity index; OR, odds ratio; MD, mean difference; AE, adverse event; SAE, serious adverse event; CI, confidence interval; DDAAEs, discontinuation due to any AEs; HLA, human leukocyte antigen; NSAID, non-steroidal anti-inflammatory drug; bDMARD, biological disease-modifying antirheumatic drugs; TNF, tumor necrosis factor; CTLA8, cytotoxic T lymphocyte antigen 8; IL-17R, IL-17 receptor; NF- $\mathrm{BB}$, nuclear factor $\mathrm{\kappa B}$; MAPK, mitogen-activated protein kinase; C/EBP, CCAAT/enhancer-binding protein; Th, T helper; SEC, secukinumab; IXE, ixekizumab; NTK, netakimab; BIM: bimekizumab

Open Access This article is licensed under a Creative Commons Attribution 4.0 International License, which permits use, sharing, adaptation, distribution and reproduction in any medium or format, as long as you give appropriate credit to the original author(s) and the source, provide a link to the Creative Commons licence, and indicate if changes were made. The images or other third party material in this article are included in the article's Creative Commons licence, unless indicated otherwise in a credit line to the material. If material is not included in the article's Creative Commons licence and your intended use is not permitted by statutory regulation or exceeds the permitted use, you will need to obtain permission directly from the copyright holder. To view a copy of this licence, visit http://creativecommons.org/licenses/by/4.0/.

\section{References}

1. Sieper J, Poddubnyy D (2017) Axial spondyloarthritis. Lancet 390:73-84

2. Braun J, Sieper J (2007) Ankylosing spondylitis. Lancet 369: $1379-1390$

3. Dougados M, Baeten D (2011) Spondyloarthritis. Lancet 377: 2127-2137

4. Stolwijk C, van Onna M, Boonen A, van Tubergen A (2016) Global prevalence of spondyloarthritis: a systematic review and meta-regression analysis. Arthritis Care Res 68:1320-1331

5. Sag S, Nas K, Sag MS et al (2018) Relationship of work disability between the disease activity, depression and quality of life in patients with ankylosing spondylitis. J Back Musculoskelet Rehabil 31:499-505

6. Kruger K, von Hinuber U, Meier F et al (2018) Ankylosing spondylitis causes high burden to patients and the healthcare system: results from a German claims database analysis. Rheumatol Int 38:2121-2131

7. de BJ, Polman A, De B-M (1961) Hereditary factors in rheumatoid arthritis and ankylosing spondylitis. Ann Rheum Dis 20:215-220

8. Brewerton DA, Hart FD, Nicholls A, Caffrey M, James DC, Sturrock RD (1973) Ankylosing spondylitis and HL-A 27. Lancet 1:904-907

9. Dagfinrud, H., T.K. Kvien, and K.B. Hagen (2008) Physiotherapy interventions for ankylosing spondylitis. Cochrane Database Syst Rev Cd002822

10. Van Der Heijde, D., S. R Ramiro (2017) Annals of the Rheumatic Diseases 76:978-991

11. Ward MM, Deodhar A, Akl EA, Lui A, Ermann J, Gensler LS, Smith JA, Borenstein D, Hiratzka J, Weiss PF, Inman RD, Majithia V, Haroon N, Maksymowych WP, Joyce J, Clark BM, Colbert RA, Figgie MP, Hallegua DS, Prete PE, Rosenbaum JT, Stebulis JA, van den Bosch F, Yu DTY, Miller AS, Reveille JD, Caplan L (2016) American College of Rheumatology/Spondylitis Association of America/Spondyloarthritis Research and Treatment Network 2015 recommendations for the treatment of ankylosing spondylitis and nonradiographic axial spondyloarthritis. Arthritis Rheumatol 68:282-298

12. Bunte, K. and T. Beikler (2019) Th17 Cells and the IL-23/IL-17 axis in the pathogenesis of periodontitis and immune-mediated inflammatory diseases. Int J Mol Sci 20

13. Lubberts E (2015) The IL-23-IL-17 axis in inflammatory arthritis. Nat Rev Rheumatol 11:415-429

14. Suzuki E, Mellins ED, Gershwin ME, Nestle FO, Adamopoulos IE (2014) The IL-23/IL-17 axis in psoriatic arthritis. Autoimmun Rev 13:496-502

15. Rouvier E, Luciani MF, Mattei MG et al (1993) CTLA-8, cloned from an activated $\mathrm{T}$ cell, bearing AU-rich messenger RNA instability sequences, and homologous to a herpesvirus saimiri gene. J Immunol 150:5445-5456

16. Taams LS, Steel KJA, Srenathan U, Burns LA, Kirkham BW (2018) IL-17 in the immunopathogenesis of spondyloarthritis. Nat Rev Rheumatol 14:453-466

17. Gaffen SL (2009) Structure and signalling in the IL-17 receptor family. Nat Rev Immunol 9:556-567 
18. Frleta M, Siebert S, McInnes IB (2014) The interleukin-17 pathway in psoriasis and psoriatic arthritis: disease pathogenesis and possibilities of treatment. Curr Rheumatol Rep 16:414

19. Zhu S, Qian Y (2012) IL-17/IL-17 receptor system in autoimmune disease: mechanisms and therapeutic potential. Clin Sci (Lond) 122:487-511

20. Shen H, Goodall JC, Hill Gaston JS (2009) Frequency and phenotype of peripheral blood Th17 cells in ankylosing spondylitis and rheumatoid arthritis. Arthritis Rheum 60:1647-1656

21. Wendling D, Cedoz JP, Racadot E, Dumoulin G (2007) Serum IL17, BMP-7, and bone turnover markers in patients with ankylosing spondylitis. Joint Bone Spine 74:304-305

22. Jandus C, Bioley G, Rivals JP, Dudler J, Speiser D, Romero P (2008) Increased numbers of circulating polyfunctional Th17 memory cells in patients with seronegative spondylarthritides. Arthritis Rheum 58:2307-2317

23. Limon-Camacho L, Vargas-Rojas MI, Vazquez-Mellado J et al (2012) In vivo peripheral blood proinflammatory T cells in patients with ankylosing spondylitis. J Rheumatol 39:830-835

24. Kenna TJ, Davidson SI, Duan R, Bradbury LA, McFarlane J, Smith M, Weedon H, Street S, Thomas R, Thomas GP, Brown MA (2012) Enrichment of circulating interleukin-17-secreting interleukin-23 receptor-positive gamma/delta $\mathrm{T}$ cells in patients with active ankylosing spondylitis. Arthritis Rheum 64:1420-1429

25. Mei Y, Pan F, Gao J, Ge R, Duan Z, Zeng Z, Liao F, Xia G, Wang S, Xu S, Xu J, Zhang L, Ye D (2011) Increased serum IL-17 and IL23 in the patient with ankylosing spondylitis. Clin Rheumatol 30: 269-273

26. Appel H, Maier R, Wu P, Scheer R, Hempfing A, Kayser R, Thiel A, Radbruch A, Loddenkemper C, Sieper J (2011) Analysis of IL$17(+)$ cells in facet joints of patients with spondyloarthritis suggests that the innate immune pathway might be of greater relevance than the Th17-mediated adaptive immune response. Arthritis Res Ther 13:R95

27. Dubash S, Bridgewood C, McGonagle D, Marzo-Ortega H (2019) The advent of IL-17A blockade in ankylosing spondylitis: secukinumab, ixekizumab and beyond. Expert Rev Clin Immunol $15: 123-134$

28. Leonardi C, Matheson R, Zachariae C, Cameron G, Li L, EdsonHeredia E, Braun D, Banerjee S (2012) Anti-interleukin-17 monoclonal antibody ixekizumab in chronic plaque psoriasis. N Engl J Med 366:1190-1199

29. Genovese MC, Durez P, Richards HB, Supronik J, Dokoupilova E, Mazurov V, Aelion JA, Lee SH, Codding CE, Kellner H, Ikawa T, Hugot S, Mpofu S (2013) Efficacy and safety of secukinumab in patients with rheumatoid arthritis: a phase II, dose-finding, doubleblind, randomised, placebo controlled study. Ann Rheum Dis 72: 863-869

30. Hueber, W., D.D. Patel, T. Dryja, et al (2010) Effects of AIN457, a fully human antibody to interleukin-17A, on psoriasis, rheumatoid arthritis, and uveitis. Sci Transl Med 2:52ra72

31. Targan SR, Feagan B, Vermeire S, Panaccione R, Melmed GY, Landers C, Li D, Russell C, Newmark R, Zhang N, Chon Y, Hsu YH, Lin SL, Klekotka P (2016) A randomized, double-blind, placebo-controlled phase 2 study of brodalumab in patients with moderate-to-severe Crohn's disease. Am J Gastroenterol 111: 1599-1607

32. Baeten D, Baraliakos X, Braun J, Sieper J, Emery P, van der Heijde D, McInnes I, van Laar JM, Landewé R, Wordsworth P, Wollenhaupt J, Kellner H, Paramarta J, Wei J, Brachat A, Bek S, Laurent D, Li Y, Wang YA, Bertolino AP, Gsteiger S, Wright AM, Hueber W (2013) Anti-interleukin-17A monoclonal antibody secukinumab in treatment of ankylosing spondylitis: a randomised, double-blind, placebo-controlled trial. Lancet 382:1705-1713

33. Deodhar AA, Dougados M, Baeten DL, Cheng-Chung Wei J, Geusens P, Readie A, Richards HB, Martin R, Porter B (2016)
Effect of secukinumab on patient-reported outcomes in patients with active ankylosing spondylitis a phase III randomized trial (MEASURE 1). Arthritis \& Rheumatology 68:2901-2910

34. Deodhar A, Poddubnyy D, Pacheco-Tena C, Salvarani C, Lespessailles E, Rahman P, Järvinen P, Sanchez-Burson J, Gaffney K, Lee EB, Krishnan E, Santisteban S, Li X, Zhao F, Carlier H, Reveille JD, COAST-W Study Group (2019) Efficacy and safety of ixekizumab in the treatment of radiographic axial spondyloarthritis: sixteen-week results from a phase III randomized, double-blind, placebo-controlled trial in patients with prior inadequate response to or intolerance of tumor necrosis factor inhibitors. Arthritis and Rheumatology 71:599-611

35. Erdes S, Nasonov E, Kunder E et al (2019) Primary efficacy of netakimab, a novel interleukin-17 inhibitor, in the treatment of active ankylosing spondylitis in adults. Clin Exp Rheumatol

36. Huang, F., F. Sun, W. Wan, et al (2019) Secukinumab provides rapid and significant improvement in the signs and symptoms of ankylosing spondylitis: primary (16-week) results from a phase 3 China-centric study, measure 5. Annals of the Rheumatic Diseases 78 (Supplement 2):894-895

37. Kivitz AJ, Wagner U, Dokoupilova E, Supronik J, Martin R, Talloczy Z, Richards HB, Porter B (2018) Efficacy and safety of secukinumab $150 \mathrm{mg}$ with and without loading regimen in ankylosing spondylitis: 104-week results from MEASURE 4 study. Rheumatology and Therapy 5:447-462

38. Pavelka, K., A. Kivitz, E. Dokoupilova, et al (2017) Efficacy, safety, and tolerability of secukinumab in patients with active ankylosing spondylitis: a randomized, double-blind phase 3 study, MEASURE 3. Arthritis Research and Therapy 19 (1) (no pagination)

39. Sieper J, Deodhar A, Marzo-Ortega H, Aelion JA, Blanco R, JuiCheng T, Andersson M, Porter B, Richards HB, MEASURE 2 Study Group (2017) Secukinumab efficacy in anti-TNF-naive and anti-TNF-experienced subjects with active ankylosing spondylitis: results from the MEASURE 2 study. Ann Rheum Dis 76:571-575

40. van der Heijde D, Cheng-Chung Wei J, Dougados M, Mease P, Deodhar A, Maksymowych WP, van den Bosch F, Sieper J, Tomita T, Landewé R, Zhao F, Krishnan E, Adams DH, Pangallo B, Carlier H, COAST-V study group (2018) Ixekizumab, an interleukin-17A antagonist in the treatment of ankylosing spondylitis or radiographic axial spondyloarthritis in patients previously untreated with biological disease-modifying anti-rheumatic drugs (COAST-V): 16 week results of a phase 3 randomised, double-blind, activecontrolled and placebo-controlled trial. Lancet 392:2441-2451

41. Van Der Heijde, D., L.S. Gensler, A. Deodhar, et al (2019) Dual neutralisation of IL-17A and IL-17F with bimekizumab was associated with improvements in patient-reported and quality-of-life outcomes in patients with active ankylosing spondylitis: results from a phase $2 \mathrm{~B}$, randomised, double-blind, placebo-controlled, dose-ranging study. Annals of the Rheumatic Diseases 78 (Supplement 2):193

42. Ungprasert P, Erwin PJ, Koster MJ (2017) Indirect comparisons of the efficacy of biological agents in patients with active ankylosing spondylitis: a systematic review and meta-analysis. Clin Rheumatol 36:1569-1577

43. Chen C, Zhang X, Xiao L, Zhang XS, Ma XL (2016) Comparative effectiveness of biologic therapy regimens for ankylosing spondylitis: a systematic review and a network meta-analysis. Medicine (Baltimore) 95:e3060

44. Cumpston, M., T. Li, M.J. Page, et al (2019) Updated guidance for trusted systematic reviews: a new edition of the Cochrane Handbook for Systematic Reviews of Interventions. Cochrane Database Syst Rev 10:Ed000142

45. Baraliakos X, Kivitz AJ, Deodhar AA, Braun J, Wei JC, Delicha EM, Talloczy Z, Porter B, MEASURE 1 Study Group (2018) Long-term effects of interleukin-17A inhibition with secukinumab 
in active ankylosing spondylitis: 3-year efficacy and safety results from an extension of the phase 3 MEASURE 1 trial. Clin Exp Rheumatol 36:50-55

46. Braun J, Baraliakos X, Deodhar A, Poddubnyy D, Emery P, Delicha EM, Talloczy Z, Porter B (2019) Secukinumab shows sustained efficacy and low structural progression in ankylosing spondylitis: 4-year results from the MEASURE 1 study. Rheumatology (Oxford) 58:859-868

47. Baraliakos X, Braun J, Deodhar A, Poddubnyy D, Kivitz A, Tahir H, van den Bosch F, Delicha EM, Talloczy Z, Fierlinger A (2019) Long-term efficacy and safety of secukinumab $150 \mathrm{mg}$ in ankylosing spondylitis: 5-year results from the phase III MEASURE 1 extension study. RMD Open 5:e001005

48. Braun J, Baraliakos X, Deodhar A, Baeten D, Sieper J, Emery P, Readie A, Martin R, Mpofu S, Richards HB, MEASURE 1 study group (2017) Effect of secukinumab on clinical and radiographic outcomes in ankylosing spondylitis: 2-year results from the randomised phase III MEASURE 1 study. Ann Rheum Dis 76: 1070-1077

49. Baraliakos X, Borah B, Braun J, Baeten D, Laurent D, Sieper J, Emery P, McInnes IB, van Laar JM, Wordsworth P, Wollenhaupt J, Kellner H, Colin L, Vandenhende F, Radford K, Hueber W (2016) Long-term effects of secukinumab on MRI findings in relation to clinical efficacy in subjects with active ankylosing spondylitis: an observational study. Ann Rheum Dis 75:408-412

50. Marzo-Ortega H, Sieper J, Kivitz A, Blanco R, Cohen M, Martin R, Readie A, Richards HB, Porter B, on behalf of the Measure 2 Study Group (2017) Secukinumab and sustained improvement in signs and symptoms of patients with active ankylosing spondylitis through two years: results from a phase III study. Arthritis Care Res (Hoboken) 69:1020-1029

51. Marzo-Ortega H, Sieper J, Kivitz A, Blanco R, Cohen M, Delicha EM, Rohrer S, Richards H (2017) Secukinumab provides sustained improvements in the signs and symptoms of active ankylosing spondylitis with high retention rate: 3-year results from the phase III trial, MEASURE 2. RMD Open 3:e000592

52. Dougados, M., J.C. Wei, R. Landewe, et al (2019) Efficacy and safety of ixekizumab through 52 weeks in two phase 3, randomised, controlled clinical trials in patients with active radiographic axial spondyloarthritis (COAST-V and COAST-W). Ann Rheum Dis

53. Erichsen, C.Y., P. Jensen, and K. Kofoed (2019) Biologic therapies targeting the interleukin (IL)-23/IL-17 immune axis for the treatment of moderate-to-severe plaque psoriasis: a systematic review and meta-analysis. J Eur Acad Dermatol Venereol

54. Loft, N.D., S. Vaengebjerg, A.S. Halling, et al (2019) Adverse events with IL-17 and IL-23 inhibitors for psoriasis and psoriatic arthritis: a systematic review and meta-analysis of phase III studies. J Eur Acad Dermatol Venereol

55. Kunwar S, Dahal K, Sharma S (2016) Anti-IL-17 therapy in treatment of rheumatoid arthritis: a systematic literature review and meta-analysis of randomized controlled trials. Rheumatol Int 36: 1065-1075

56. Purmonen T, Puolakka K, Mishra D, Gunda P, Martikainen J (2019) Cost-effectiveness of secukinumab compared to other biologics in the treatment of ankylosing spondylitis in Finland. Clinicoecon Outcomes Res 11:159-168

57. Goeree R, Chiva-Razavi S, Gunda P, Jain M, Jugl SM (2019) Costeffectiveness analysis of secukinumab in ankylosing spondylitis from the Canadian perspective. J Med Econ 22:45-52

58. Citera, G., P.M. Bianculli, A. Khare, et al (2018) Cost-effectiveness of secukinumab versus other biologics in the treatment ofankylosing spondylitis: an Argentinean perspective. Journal of Clinical Rheumatology 24 (3 Supplement 1):S117

59. Marzo-Ortega, H., A. Halliday, S. Jugl, et al (2017) The costeffectiveness of secukinumab versus tumour necrosis factor a inhibitor biosimilars for ankylosing spondylitis in the UK. Rheumatology (United Kingdom) 56 (Supplement 2):ii92

60. Fedyaev D, Derkach EV (2016) Cost-effectiveness analysis of different biologic agents for ankylosing spondylitis treatment in Russia. Value Health 19(7):A539

Publisher's note Springer Nature remains neutral with regard to jurisdictional claims in published maps and institutional affiliations. 